UDC 316.334.3:321

LBC 60.561 .32

\title{
SOCIAL STATE BUILDING AS THE KEY RESOURCE OF HARMONIZATION INTERETHNIC RELATIONS IN RUSSIA
}

\author{
Richard Arami Danakari \\ Volgograd Institute of Management, Branch of the Russian Academy of National Economy \\ and Public Service under the President of Russia, Volgograd, Russian Federation
}

\begin{abstract}
The study of contemporary Russian reality, the political and socio-economic system, the human existence and its spiritual and moral values actualizes the interest for the theory and practice of the social state prevailing in the developed countries of different continents. As the author mentions this fact is determined by the presence of a huge number of problems and "challenges" for the Russian state and society. The social dynamics non-linearity, uncertainties and risks, increased tension and conflict in the global, regional and local space, "color revolutions," the growth of ethnocentrism and migrant phobia, extremism and terrorism are among them. In addition to the mentioned above the issues and the very specificity of the formation of an active civil society, the possibility of forming confidence between the authorities, business and the society still remains topical. The state and prospects of federalism development, peculiarities of the state national, demographic, migration policy implementation, ways of interethnic relations harmonization give rise to concern.

In modern Russia in terms of a periodically repeating crisis and the society state deterioration, the need to build a social state is becoming more and more popular. The author believes that such work requires a radical transformation of the currently existing political, social and economic, civilizational and spiritual and moral life of society paradigm that only this reform will de facto contribute to the transformation of the man into a higher purpose and value of the real subject of social dynamics. This will open real prospects for the multiethnic and multiconfessional Russian society, which will help to mobilize it, to overcome the systemic crisis and to move towards the formation of common cultural identity and the consolidated Russian nation.
\end{abstract}

Key words: radical transformation of the social state, the Russian nation, ethnic relations, partnership, solidarism.

УДК $316.334 .3: 321$

ББК 60.561 .32

\section{СТРОИТЕЛЬСТВО СОЦИАЛЬНОГО ГОСУДАРСТВА - КЛЮЧЕВОЙ РЕСУРС ГАРМОНИЗАЦИИ МЕЖЭТНИЧЕСКИХ ОТНОШЕНИЙ В РОССИИ}

\author{
Ричард Арами Данакари \\ Волгоградский институт управления - филиал Российской академии народного хозяйства \\ и государственной службы при Президенте России, г. Волгоград, Российская Федерация
}

\footnotetext{
Аннотация. Исследование современной российской действительности, политической и социально-экономической системы, бытия человека и его духовно-нравственных ценностей с необходимостью актуализирует интерес к теории и практике социального государства, существующего в развитых странах мира на разных континентах. Как подчеркивает автор, он детерминирован наличием огромного количества проблем и «вызовов» для российского государства и общества. В их числе: нелинейность социальной динамики, неопределенность и риски, усиление напряженности и конфликтов в глобальном, региональном и локальном пространстве, «цветные революции», нарастание этноцентризма и мигрантофобии, экстремизма и терроризма. В дополнение к ним, для нашей страны все еще злободневными остаются вопросы и сама специфика формирования активно функционирующего гражданского общества, возможности обеспечения доверия между властью, бизнесом и социумом. Вызывают тревогу состояние и перспективы развития федерализма, особенности реализации государственной () национальной, демографической, миграционной политики, пути гармонизации межэтнических отношений.
} 
В современной России, в условиях периодически повторяющегося кризиса и ухудшения состояния общества, все более очевидной становится необходимость строительства социального государства. По мнению автора, такая работа предполагает радикальную трансформацию ныне существующей политической, социально-экономической, цивилизационной и духовно-нравственной парадигмы бытия государства и социума, что только она де-факто будет способствовать превращению человека в высшую цель и ценность, в реального субъекта общественной динамики. В результате перед полиэтническим и поликонфессиональным российским обществом откроются реальные перспективы, позволяющие мобилизовать его, преодолеть системный кризис, двигаться по пути формирования общекультурной идентичности и единой российской нации.

Ключевые слова: радикальная трансформация, социальное государство, российская нация, межэтнические отношения, партнерство, солидаризм.

За последние десятилетия российское общество периодически оказывалось в условиях социально-экономического кризиса. Продолжающееся постепенное разрушение культурного кода и падение нравственного уровня российского социума свидетельствуют о недовольстве определенной части населения страны существующим положением дел. В обществе нарастают напряжение и отчуждение, агрессия и экстремизм, оно становится все более расколотым и фрагментарным. Сегодня для научного сообщества все более актуальной становится проблема изучения реального состояния России как многонационального и поликонфессионального сообщества народов, определения путей и перспектив ее развития как федеративного государства.

Изучение феномена социального государства и необходимость его строительства в России значимы в связи с низкой эффективностью функционирования политической, социально-экономической и культурной систем, необходимостью научного осмысления и выработки адекватной стратегии развития.

В работе ставится задача по исследованию реального состояния современного российского общества, определению ключевых подходов к строительству в нашей стране социального государства, выявлению его оснований, характеристик, специфики. Признание исключительности, приоритетности интересов многонационального российского народа может составить важный ресурс для строительства социального государства, обеспечить движение к интеграции общества и формирование новой общекультурной идентичности.

В числе важных задач: во-первых, анализ и выявление опыта развитых стран мира
(ФРГ, Франции, США, Канады) по строительству социального государства, возможности его применения в России; во-вторых, определение основной цели и подходов по разработке и реализации собственной модели социально ориентированной рыночной экономики; в-третьих, изучение традиций развитых стран мира по взаимодействию между государством и обществом, обеспечению доверия, социального партнерства и равноправного диалога между властью, бизнесом и профсоюзами. Все это может снять социальную напряженность и заложить основы для гармонизации межэтнических отношений.

Сегодня, в условиях усиливающейся глобализации мира, для Российской Федерации важно найти ответы на «вызовы времени», особенно следующего характера: каковы пути развития и перспективы будущего нашего многонационального государства? Насколько востребовано в России строительство социального государства? Как наша бюрократия и чиновничество могут изменить свою природу и сущность, реально служить обществу?

На наш взгляд, единственным выходом из сложившейся ситуации может стать трансформация внутренней политики, обеспечение приоритетности интересов многонационального российского общества. Качественные изменения необходимы для выхода из существующего кризиса и осмысления реалий сформировавшегося «нового мирового порядка», определения путей и перспектив развития страны [6, с. 13]. В этих условиях актуальный характер приобретает изучение исторического опыта возникновения, становления и развития социального государства в передовых странах мира, особенно в Западной Европе и США. 
Обращаясь к истории проблемы, отметим, что в современной науке приоритет в разработке понятия «социальное государство» принадлежит немецкому экономисту Лоренцу фон Штайну. По его мнению, социальное государство «...обязано способствовать экономическому и общественному прогрессу всех своих граждан, ибо, в конечном счете, развитие одного выступает условием развития другого, и именно в этом смысле говорится о социальном государстве» $[12$, с. 82$]$. Как считал ученый, в условиях капитализма классовая борьба неизбежна. Значит, единственным выходом может стать поиск баланса интересов между различными социальными группами и слоями. Главным субъектом такой деятельности может быть только государство, решающее задачи по обеспечению социальной мобильности, перехода из одного класса в другой, реальной поддержки тех, кто особенно нуждается в ней. Основной целью социального государства, согласно учению Штайна, становится сохранение социальной и политической стабильности в обществе, обеспечение непрерывности его развития.

Одним из авторов и руководителей немецкого «экономического чуда» был бывший канцлер ФРГ Людвиг Эрхард. Как активный сторонник государственного регулирования рыночной экономики, он в числе основных требований для формирования нового социальноэкономического порядка признал создание массовой покупательной способности, обеспечение конкуренции, постоянное повышение заработной платы, создание условий для всеобщего благосостояния [15]. Именно такая политика может обеспечить взаимосвязь и баланс между рынком и общественным порядком и позволит особое внимание уделить социальной направленности экономики. В результате конечной целью рыночного хозяйствования в ФРГ стало специфическое государственное регулирование, сочетание административных и рыночных методов, словом, подчинение экономики интересам всех ее участников, а не только крупных собственников.

Со второй половины XX в. как теория, так и практика социального государства претерпели существенные изменения в различных западных направлениях и течениях либерализма, консерватизма и социал-демократии. Во многом они были связаны с периодически повторяющимися экономическими кризисами, борьбой трудящихся разных отраслей и их профсоюзов за свои права. Другим важным фактором стало то, что передовая часть интеллигенции и элит западных стран осознала неизбежность и объективность непрерывных изменений, касающихся развития социальной и экономической демократии, наделения работников правами в управлении предприятиями, участия их в акционировании, обеспечения равноправного диалога между предпринимателями и тружениками, бизнесом и профсоюзами. Часто изменения шли параллельно, они происходили как в обществах с социально ориентированной рыночной экономикой, «государствах всеобщего благоденствия», так и в общественном сознании народов этих стран.

Заметим, что само понятие «государство благоденствия» имеет разные модификации. Например, в США сформировалось «позитивное государство социальной защиты». В своей основе оно опирается на свободу и индивидуальное развитие человека, защиту корпоративных интересов, однако не гарантирует всем гражданам достаточно высокий уровень жизни. В Великобритании, в отличие от других стран, сформировалось «государство социальной безопасности». В нем были предприняты попытки обеспечить полную занятость населения; заработная плата и доход должны быть не ниже прожиточного минимума. Словом, со стороны государства были гарантированы не материальные блага, а равные социальные возможности. В Швеции появилась модель под названием «социальное государство всеобщего благоденствия», которое не только продекларировало, но и на самом высоком уровне обеспечило равенство, солидарность, партнерство [9, с. 102-103].

Однако несмотря на значительные достижения, особенно в области обеспечения материальных благ, почти во всех развитых странах объективно появилась необходимость изменения основных парадигм внутренней жизни и внешнеполитической деятельности социального государства [13, с. 24]. Они были обусловлены как государственной политикой и всем социальным бытием западных обществ, так и специфическими принципами и подходами неоглобализма, появлением транс- 
национальных корпораций и новыми «вызовами». Во многом эти изменения стали возможны «благодаря» кризису и распаду СССР, трансформации геополитической карты мира.

С конца XX в. постепенно стали меняться внутриполитические приоритеты развитых стран, начались наступления государства на социальные права трудящихся, завоеванные ими в прошлом. Для развитых стран Западной Европы определенную угрозу стали представлять непрерывные волны миграции, этнические и расовые конфликты. Сегодня в них озабочены фиаско теорий и политики толерантности и мультикультурализма. Концепция «плавильного котла» породила серьезные проблемы и в одном из могущественных государств мира, стране, объявившей себя победителем в холодной войне - Соединенных Штатах Америки.

Отметим, что в сформировавшихся социальных государствах Запада в центре основного внимания были задачи по созданию нового, потребительского общества. Они были заинтересованы в снижении социальной напряженности и минимизации общественных конфликтов путем обеспечения высокого материального достатка для большинства населения. Одновременно либерализм изменил своим высоким принципам рационализма периода Нового времени и Просвещения, касавшимся приоритетности разума, свободы, равенства, справедливости и братства людей. Для сохранения господства и удержания власти стал использоваться иррационализм, наступило время человека-массы, время удовлетворения его природно-биологических интересов, низменных инстинктов и примитивных культурных стандартов.

Формирование информационного общества позволило использовать более изощренные способы манипулирования общественным мнением и воздействия на психологию и подсознание масс. Становление социального государства не сопровождалось развитием высокого уровня культуры в обществе, нравственности человека, особенно - превращением рыночного, эгоцентристского типа индивида в высокоразвитую личность. В результате реализации политики толерантности и мультикультурализма в западных государствах появились целые районы, отдель- ные анклавы, где функционировали замкнутые расовые и этнические группы, что усилило противостояние, агрессию и вражду между людьми.

Обращаясь к российской действительности, отметим, что ее анализ и диагноз с необходимостью актуализирует интерес к теории и практике социального государства развитых стран мира. Он детерминирован наличием огромного количества современных «вызовов» для российского государства и общества. Перед страной и ее элитой стоят сложные задачи по преодолению не только общего кризиса, но и решению целого комплекса проблем. Они связаны не только с обеспечением высокого уровня и качества жизни, что реализовано в развитых странах и представляет для нас интерес, но и с сохранением и развитием своего культурного кода, высоких духовно-нравственных ценностей.

Для наступившей эпохи постмодерна, захватившей частично и нашу страну, характерными стали: неопределенность и риски, нелинейность социальной динамики, «цветные революции» на планете, усиление напряженности и конфликтов в глобальном, региональном и локальном пространстве, «столкновение» культур и цивилизаций, этническая мобильность и миграционные волны. Для современной России, в дополнение к ним, все еще злободневными остаются вопросы формирования активно функционирующего гражданского общества, обеспечения доверия между властью, бизнесом и социумом. Вызывают тревогу состояние и перспективы развития федерализма, особенности реализации государственной национальной, демографической, миграционной политики, пути гармонизации межэтнических отношений.

Что сегодня представляет собой Российская Федерация как метафизическая субстанция и объективная реальность? Насколько она может позиционировать себя в мире как уникальная цивилизация, содружество народов, языков, культур и религий? Возможно ли строительство социального государства в России, в стране с такой сложной полиэтнической и поликонфессиональной структурой? В контексте современных глобальных и региональных процессов «ответы» на эти «вызовы» приобретают исключительное значение. Они свя- 
заны не просто с ролью и местом российской цивилизации в мире, но касаются судьбы и будущего нашего государства и общества.

Обращение к эпохе СССР свидетельствует о том, что в нашей стране теория социального государства практически не разрабатывалась. Априори считалось, что в Советском Союзе сформировано справедливое государственное и общественное устройство, что данная точка зрения не требует научного обоснования. Как известно, советская модель социализма, сложившаяся общественно-политическая система не выдержала испытание временем. После распада СССР прошло несколько десятилетий. Однако периодически в современной России происходят кризисы социально-экономической и валютно-финансовой систем.

Напомним, что в ст. 7 Конституции РФ от 12 декабря 1993 г. записано, что «Российская Федерация - социальное государство, политика которого направлена на создание условий, обеспечивающих достойную жизнь и свободное развитие человека» [5, с. 7]. Нам представляется, что наступило время для реального изменения политической, экономической и социокультурной стратегии развития страны. На повестку дня встал вопрос разработки и реализации на практике российской модели социального государства, активное осуществление модернизации и ускорение развития информационного общества.

Отметим, что в конце XX в. понятие «социальное государство» находилось в центре внимания российской философии и общественных наук. Однако научные дискуссии и полемики, продолжающиеся долгие годы на страницах журналов, заседаниях политических партий, органов власти, многочисленных конференциях, дали очень мало для реального продвижения, как в теории, так и на практике $[11$, c. 5-14]. Во многом политизация и идеологизация не способствовали системному постижению данного феномена, разработке в соответствии с российской спецификой реальной модели социального государства, определению его места в системе международных отношений и глобализирующегося мира [8, c. 169-182].

На наш взгляд, важнейшим препятствием для понимания идеи и политики социаль- ного государства стало то, что появившиеся элиты не осознали актуальность постановки и решения такой задачи. А главное - вне пространства как научной мысли, так и практики, оказался человек как реальный субъект государства и общества, главный ресурс социально-экономического и духовно-нравственного возрождения и развития России. Не случайно, что в нашей стране все еще сохраняется традиционное понимание социального государства как института перераспределения национального дохода.

Российская модель социального государства должна включать специфическую деятельность государства по строительству реальной социально ориентированной рыночной экономики, активную общественную, а главное - субъектную составляющую, опираться на высокие гуманистические принципы. Наверное, не следует бояться обращаться к советскому опыту, творчески использовать опыт строительства социализма, заранее выявляя границы и пределы вмешательства государства во все сферы общества.

Современное государство не только может, но и обязано активно реагировать на постоянно возникающие ситуации, запросы и интересы общества. Оно должно брать на себя ответственность за решение стратегических задач, связанных с удовлетворением важнейших потребностей общества, так как имеет в своем распоряжении ресурсы, силы и средства. Следует согласиться с точкой зрения В. Анисимова, который рассматривает социальное государство как «правовое демократическое государство, которое провозглашает высшей ценностью человека и создает условия для достойной жизни, свободного развития и самореализации творческого (трудового) потенциала личности. Понятие достойной жизни предполагает материальную обеспеченность на уровне стандартов, отвечающих потребностям современного общества, доступ к ценностям культуры, гарантированность прав личной безопасности, свободное развитие человека - его физическое, умственное и нравственное совершенствование» [1, с. 39].

«Очевидно, что в обозримой перспективе роль государства в социальной сфере глобализирующихся обществ не только не умень- 
шится, но, напротив, существенно увеличится» [8, с. 179]. Поэтому объективным и закономерным является процесс усиления государством части своих функций, преимущества которого проверены временем и опытом развитых стран. Конечно, государству не следует выполнять всеохватывающие или, наоборот, узкоспециализированные функции. Ему следует сосредотачиваться на координации институциональных взаимодействий в тех сферах, что увеличивает авторитет и компетентность государства, превращая его в основного субъекта - носителя социальной миссии $[2$, с. 28$]$.

Сегодня прогрессивную сущность социального государства следует выявлять на основе развития производительных сил общества, качества жизни и высокой культуры человека. Общественное развитие невозможно остановить, оно приобретает все больший динамизм, поэтому строительство социального государства в России следует рассматривать как объективный и закономерный процесс. Гарантией стабильного и динамичного развития России должен быть объективный процесс эволюции государства в сторону новой социальной модели бытия, реального гуманизма, высокой культуры и нравственности.

В настоящее время в России идеи социализма дискредитированы, поэтому актуальный характер приобретает пропаганда теории и практики социального государства с российской спецификой. Конечно, важно использовать позитивный опыт развитых стран мира, где обеспечен высокий уровень услуг и качество материального бытия человека.

Одновременно строительство социального государства можно рассматривать и как некий идеал, своеобразную конструктивистскую модель. Следует согласиться с И.В. Леоновым, который пишет: «Социальное государство - это тот идеал, к которому человечество стремится на протяжении веков, это идеальный тип государства, деятельность которого основана на признании, соблюдении и гарантированной защите политических и социально-экономических прав и высших духовно-нравственных ценностей» $[10$, с. 12$]$.

Общество может считаться развитым и демократическим, если государство в своей деятельности опирается на законы, способствует развитию прав и свобод человека, уровня его культуры и нравственности. Следует согласиться с мнением С.В. Калашникова, который пишет, что на современном этапе социальное государство представляет собой особый тип высокоразвитого государства, в котором обеспечивается высокий уровень социальной защищенности всех граждан посредством активной деятельности государства по регулированию социальной, экономической и других сфер жизнедеятельности общества, установлению в нем социальной справедливости и солидарности $[4$, с. 52$]$.

На наш взгляд, разработка и реализация российской модели социального государства обеспечит: во-первых, приоритет экономикотехнологической и информационной сфер в развитии общества, которые станут ведущими в системе непрерывной социальной динамики; во-вторых, осуществление новой политической модернизации, реальное разделение властей, учет объективных требований политических партий, оппозиционных сил, независимых СМИ, движение к строительству демократического и правового государства, записанного в основном законе страны; в-третьих, социальную модернизацию, реальный трипартизм, равноправный диалог между властью, бизнесом и обществом, формирование подлинно функционирующего гражданского общества, приоритетность всей социальной сферы, особенно гарантию прав человека на труд и достойную жизнь, реализацию основных статей Конституции Российской Федерации, посвященных человеку; в-четвертых, динамику в сфере культурной модернизации, где в центре внимания окажется проблема поиска общенациональной цели, надэтнических и надконфессиональных ценностей, что позволит определить пути и перспективы формирования общецивилизационной идентичности. Решение этих проблем качественно улучшит геополитическое положение России в евразийском пространстве, позволит активно защищать национальные интересы страны, занять ведущее место в глобализирующемся мире.

Признавая особенности страны, в 2013 г. Президент РФ В.В. Путин в своей речи в международном клубе «Валдай» отметил: «...идентификация исключительно через этнос, рели- 
гию в крупнейшем государстве с полиэтническим составом населения, безусловно, невозможна. Формирование именно гражданской идентичности на основе общих ценностей, патриотического сознания, гражданской ответственности и солидарности, уважения к закону, сопричастности к судьбе Родины без потери связи со своими этническими, религиозными корнями - необходимое условие сохранения единства страны» [3].

Завершая исследование, посвященное необходимости строительства социального государства в России, хотелось бы обратить внимание еще на ряд моментов, связанных с общественной динамикой в России нового столетия. Важнейшей ее особенностью становится все еще продолжающаяся разновекторность интересов общества и государственной бюрократии, господство неолиберальной теории и ее неадекватность реальной практике, бытию общества и личности.

Продолжающееся разрушение политического и экономического, социокультурного бытия, основ гуманизма и морали, сущности человека превращает людей в продукт манипуляции властью, которая не просто обманывает людей, а стремится делать их такими, как ей нужно. Обработке подвергаются при этом мысли, происходит манипулирование не только сознанием, но и волей, телесными желаниями и потребностями. Все это результат «застоя», отказа от идеи человека как высшей ценности, игнорирование необходимости создания реально функционирующего гражданского общества и гармоничного развития личности. Забывается, что как природа, общество, так и человек и созданные им вещи и институты, являясь и становясь, обладают самостоятельной реальностью, развиваются по собственным законам. И эти системы, в свою очередь, предъявляют свои требования к государству, обществу, человеку и его деятельности.

Таким образом, анализ общественного бытия и сферы межнациональных отношений в России показывает востребованность в строительстве социального государства со своей спецификой, где высшей целью и ценностью станет личность, приоритетом - общекультурная идентичность, надэтническая и надконфессиональная нравственность. Как отмечали выше, идентификация исключительно через моноэтничность или религию в федеративном государстве с полиэтническим и многоконфессиональным составом населения невозможна. Реализация основных положений Стратегии государственной национальной политики РФ на период до 2025 г. способствует стабилизации общества, развитию межэтнических и федеративных отношений [14].

Строительство социального государства в России, что предполагает приоритетность интересов и потребностей многонационального сообщества, опору на русскую культуру, в центре которой - идеи социальной справедливости и высокой нравственности, учет общецивилизационных особенностей ее народов, обеспечит трансформацию внутренней политики, окажет воздействие на укрепление международного авторитета страны в мире. Отсюда значимой станет реализация всех стратегий, в том числе и целей, основных приоритетов, принципов и задач социально-экономического развития страны, государственной национальной, демографической, миграционной политики, что актуализирует необходимость формирования общекультурной идентичности и единой гражданской нации как субъекта общественно-политических отношений. Реализация данной цели позволит сохранить Российскую Федерацию как уникальную цивилизацию, придаст новый смысл бытию государства и общества, деятельности человека.

\section{СПИСОК ЛИТЕРАТУРЫ}

1. Анисимов, В. М. Стратегическая цель социальное государство / В. М. Анисимов // Человек и труд. -2009 . - № 12. - С. 32-39.

2. Васильева, Е. Э. «Социальное государство» и новая модель социальной политики / Е. Э. Васильева // Власть. - 2008. - № 11. - С. 28-34.

3. Заседание международного дискуссионного клуба «Валдай». - Электрон. текстовые дан. Режим доступа: http://www.kremlin.ru/events/ president/news/19243 (дата обращения: 19.09.2013). Загл. с экрана.

4. Калашников, С. В. Очерки теории социального государства / С. В. Калашников. - М. : Экономика, 2006. -362 c.

5. Конституция Российской Федерации : принята всенародным голосованием 12 декабря 1993 г. СПб. : Питер, 2014. - 64 с. 
6. Кочетков, В. В. Социальное государство и мировой кризис: парадигма преодоления / В. В. Кочетков // Власть. - 2009. - № 3. - С. 13-16.

7. Красин, Ю. А. Глобализация и политическое развитие России / Ю. А. Красин, А. А. Галкин // Свободная мысль. - 2009. - № 2. - С. 169-182.

8. Краснолуцкий, Г. Н. Правовое и социальное государство: политологические исследования и пути становления / Г. Н. Краснолуцкий // Управленческое консультирование. - 2009. - № 2. - С. 81-106.

9. Леонов, И. В. Современное социальное государство: сущность, признаки, проблемы формирования / И. В. Леонов. - М. : МГИМО, 2006. - 96 с.

10. Мамут, Л. С. Социальное государство с точки зрения права / Л. С. Мамут // Государство и право. -2001 . - № 7. - С. 5-14.

11. Милецкий, В. П. Социальное государство: эволюция идей, сущность и перспективы становления в современной России / В. П. Милецкий // Политические процессы в России в сравнительном измерении. СПб. : Изд-во С.-Петерб. ун-та, 1997. - С. 82-104.

12. Родионова, О. В. Современное социальное государство: типология и проблемы модернизации / О. В. Родионова // Известия вузов. Правоведение. 2010. - № 3. - С. 15-26.

13. Указ Президента Российской Федерации от 19 дек. 2012 г. № 1666 «О Стратегии государственной национальной политики России до 2025 года». Электрон. текстовые дан. - Режим доступа: http:// www.kremlin.ru/acts/bank/36512. - Загл. с экрана.

14. Эрхард, Л. Благосостояние для всех / Л. Эрхард. - М. : Начала-ПРЕСС, 1991. - 335 с.

\section{REFERENCES}

1. Anisimov V.M. Strategicheskaya tsel sotsialnoe gosudarstvo [The Strategic Goal is a Welfare State]. Chelovek i trud, 2009, no. 12. pp. 32-39.

2. Vasilyeva E.E. «Sotsialnoe gosudarstvo» i novaya model sotsialnoy politiki ["Welfare State" and a New Model of Social Policy]. Vlast, 2008, no. 11, pp. 28-34.

3. Zasedanie mezhdunarodnogo diskussionnogo kluba «Valday» [Session of Valdai International Discussion Club]. URL: http:/www.kremlin.ru/events/ president/news/19243. (accessed September 19, 2013).

4. Kalashnikov S.V. Ocherki teorii sotsialnogo gosudarstva [Essays on the Theory of Welfare State]. Moscow, Ekonomika Publ., 2006. 362 p.
5. Konstitutsiya Rossiyskoy Federatsii: (prinyata vsenarodnym golosovaniem 12 dekabrya 1993 goda) [The Constitution of the Russian Federation: (Adopted by Popular Vote on December 12, 1993)]. Saint Petersburg, Piter Publ., 2014. 64 p.

6. Kochetkov V.V. Sotsialnoe gosudarstvo i mirovoy krizis: paradigma preodoleniya [The Welfare State and the Global Crisis: Paradigm of Overcoming]. Vlast, 2009, no. 3, pp. 13-16.

7. Krasin Yu.A., Galkin A.A. Globalizatsiya i politicheskoe razvitie Rossii [Globalization and Political Development of Russia]. Svobodnaya mysl, 2009, no. 2, pp. 169-182.

8. Krasnolyutskiy G.N. Pravovoe i sotsialnoe gosudarstvo: politologicheskie issledovaniya i puti stanovleniya [Legal and Social State: Political Research and Ways of Formation]. Upravlencheskoe konsultirovanie, 2009, no. 2, pp. 81-106.

9. Leonov I.V. Sovremennoe sotsialnoe gosudarstvo: sushchnost, priznaki, problemy formirovaniya [The Modern Welfare State: Essence, Features, Problems of Formation]. Moscow, MGIMO Publ., 2006. 96 p.

10. Mamut L.S. Sotsialnoe gosudarstvo s tochki zreniya prava [The Welfare State in Terms of Law]. Gosudarstvo i pravo, 2001, no. 7, pp. 5-14.

11. Miletskiy V.P. Sotsialnoe gosudarstvo: evolyutsiya idey, sushchnost i perspektivy stanovleniya v sovremennoy Rossii [The Welfare State: Evolution of Ideas, Essence and Prospects of Formation in Modern Russia]. Politicheskie protsessy $v$ Rossii v sravnitelnom izmerenii [Political Processes in Russia in Comparative Dimension]. Saint Petersburg, Izd-vo S.-Peterb. un-ta, 1997, pp. 82-104.

12. Rodionova O.V. Sovremennoe sotsialnoe gosudarstvo: tipologiya i problemy modernizatsii [The Modern Welfare State: Typology and Modernization Issues]. Izvestiya vuzov. Pravovedenie, 2010, no. 3, pp. 15-26.

13. Ukaz Prezidenta Rossiyskoy Federatsii ot 19 dek. 2012 g. № 1666 “O Strategii gosudarstvennoy natsionalnoy politiki Rossii do 2025 goda" [The Decree of the President of the Russian Federation of December 19, 2012 no. 1666 "On the Strategy of State National Policy of the Russian Federation for the Period till 2025]. URL: http://www.kremlin.ru/events/president/ news/17165.

14. Erkhard L. Blagosostoyanie dlya vsekh [The Welfare for Everyone]. Moscow, Nachala-PRESS, 1991. $335 \mathrm{p}$. 


\section{Information About the Author}

Richard Arami Danakari, Doctor of Philosophical Sciences, Professor, Department of Philosophy and Sociology, Associate Professor, Volgograd Institute of Management, Branch of the Russian Academy of National Economy and Public Service under the President of Russia, Gagarina St., 8, 400131 Volgograd, Russian Federation, rdanakari@mail.ru.

\section{Информация об авторе}

Ричард Арами Данакари, доктор философских наук, профессор кафедры философии и социологии, доцент, Волгоградский институт управления - филиал Российской академии народного хозяйства и государственной службы при Президенте России, ул. Гагарина, 8, 400131 г. Волгоград, Российская Федерация, rdanakari@mail.ru. 